\title{
Correction to: Performance measurement for offline inspections under variable interactions and inspection errors in low-volume production
}

\author{
Elisa Verna ${ }^{1} \cdot$ Gianfranco Genta $^{1} \cdot$ Maurizio Galetto $^{1} \cdot$ Fiorenzo Franceschini ${ }^{1}$ (I)
}

Published online: 27 September 2021

(c) The Author(s) 2021

\section{Correction to: Production Engineering https://doi.org/10.1007/s11740-021-01077-9}

In the published article "Performance measurement for offline inspections under variable interactions and inspection errors in low-volume production. Prod. Eng. Res. Devel. (2021). https://doi.org/10.1007/s11740-021-01077-9" the order of author's name is given incorrectly.

Erratum: Verna Elisa, Genta Gianfranco, Galetto Maurizio \& Franceschini Fiorenzo was the Authors list in the article.

Corrige: the correct Authors list should be: Elisa Verna, Gianfranco Genta, Maurizio Galetto \& Fiorenzo Franceschini.

Erratum: the previous citation of the article was: "Elisa, V., Gianfranco, G., Maurizio, G. et al. Performance measurement for offline inspections under variable interactions and inspection errors in low-volume production. Prod. Eng. Res. Devel. (2021). https://doi.org/10.1007/ s11740-021-01077-9".

Corrige: the article should be cited as "Verna, E., Genta, G., Galetto, M., et al. Performance measurement for offline inspections under variable interactions and inspection errors in low-volume production. Prod. Eng. Res. Devel. (2021). https://doi.org/10.1007/s11740-021-01077-9".

Original article corrected.

The original article can be found online at https://doi.org/10.1007/ s11740-021-01077-9.

Fiorenzo Franceschini

fiorenzo.franceschini@polito.it

1 Department of Management and Production Engineering,

Politecnico di Torino, Corso Duca degli Abruzzi 24,

10129 Turin, Italy
Publisher's Note Springer Nature remains neutral with regard to jurisdictional claims in published maps and institutional affiliations. 